\title{
On the ability to Improve Business Marketing Strategy
}

\author{
Jin HOU \\ Beijing Polytechnic College \\ Beijing 100042, China
}

\begin{abstract}
Enterprise marketing capabilities constitute the core competitiveness of the important part. In practice, companies tend to focus on the performance perspective of corporate marketing capabilities, while ignoring the marketing resources and their ability to take advantage of the ability to influence corporate marketing leading role and importance of prior evaluation. Use fuzzy comprehensive evaluation method and combine AHP, from the perspective of marketing resources, and accurate pre-evaluation of enterprise marketing capabilities of companies can look for research to improve the weak link, the starting point for the development of new markets and attract the target consumer who maximizes to improve their market competitiveness purposes.
\end{abstract}

Keywords- Marketing Capabilities; Index System, Fuzzy Comprehensive Evaluation

\section{INTRODUCTION}

Business marketing capability as the core competitiveness of the important part is an enterprise mobilization, coordination, development of marketing resources to obtain competitive advantage of core competencies. Currently, most domestic enterprises have been fully aware of the conditions in the market economy, the survival and development of enterprises is inseparable from strong marketing, and seeks to measure the ability of the enterprise marketing from a quantitative perspective. In practice, companies tend to focus on the perspective from the performance analysis of enterprise marketing capabilities. For example, by market share, market coverage, sales margins, merchandise export growth and other indicators are to judge the ability of corporate marketing, namely, after the judge, but it ignores the marketing resources and their ability to take advantage of the leading role of the ability to influence corporate marketing, thus ignoring the importance of the pre-evaluation. Therefore, from the perspective of marketing resources and their use, and accurate pre-judge of the enterprise marketing capabilities should become the focus of interest in the business.

\section{CURRENT ISSUE OF THE CORPORATE MARKETING}

\section{A. Marketing is with Fierce Competition and Has More Difficulty}

As market competition intensifies, companies marketing strategy is able to meet market requirements, determines whether marketing to succeed or not. However, SMEs in the fierce competition of the market is to be successful, which is not very easy. In marketing, marketing companies tend to keep up with the concept of a rapidly changing market; the development of new products is difficult to play the role of the marketing network. In this process, the concept behind the corporate marketing led business to helpless in the face of a buyer's market, allowing companies to cash flow difficulties, and even leading to the emergence of semishutdown state enterprises. In this case, efficient marketing has become increasingly important. 2. Enterprises lack a marketing strategy to develop new products and new markets are relatively weak.

Some companies in the face of fierce market competition, lack strategic vision with the times, and lack new product development and new product market share. In this case, the enterprise to establish a clear marketing strategy becomes particularly important. Therefore, as a business, it should strengthen marketing in the interpretation of the market, so that enterprises can reap because grasping market information and marketing opportunities in the battle is to promote consumer-centric marketing to market as a starting point and to think about marketing strategy.

\section{B. The market as the center, establish marketing system}

Marketing is able to sell the product to the customer, and may make profit in the process, creates profits for the company. So marketers are to grasp what position the socioeconomic status of enterprises are in the chain, so that every business can do through research market positioning. On this basis of marketing personnel, through product development and sales and marketing, the company's products are accepted by the market. Therefore, marketers must master a variety of marketing data, and market segmentation based on the market required for business products. Needs of Marketing staff and customer desire to do research, and actively expand the market, so the company's products are to occupy more market share. Meanwhile, as a marketer, you want to grasp the market feedback data reported to the responsible person, which is easy to locate business enterprise goals. For example, for a cell phone industry, brand share declines rapidly comparing to certain foreign brand market share. As marketers, we must do market segmentation, consumer needed to know, and thus insufficient grasp of the enterprise, re-established marketing system.

\section{THE IMPORTANCE OF MARKETING CAPABILITY}

Corporate marketing capability is an enterprise understanding of market, integrated use of marketing mix 
strategy, organization and management of production and business activities, the ability is to expand the overall market capacity.

An enterprise, in order to grow rapidly, not only depends on its technical capabilities and production capacity, but also depends on its marketing capabilities. Lack of market penetration, lack of circulation influence, and be subject to the others, you cannot develop smoothly. Panasonic's worldfamous can get amazing development, in fact, it began to establish himself in circulation position in Japan, "Hitachi technology, the sale of Matsushita," said. Panasonic and retail outlet stop consignment contracts and business relationships, because Matsushita's strength is too small to dominate retail outlet. In the early $1950 \mathrm{~s}$, after the reorganization of the production system, Mr. Matsushita immediately set about establishing a distinctive marketing network, and created a "installment" approach, so as to make the Panasonic that has a broad prospect. The circulation penetration and consumer consumption process are closer to the scene, which is marketing the real meaning --- --- a marketing ability is to control the market, the ability of customers affected. With the increase in the production and consumption of each degree of freedom of choice, it should be replaced by unity complexity, it certainty is uncertainly replaced, stability replaced instability, continuity substituted discontinuity, so that for the production people generally had weakening predictability, consumers generally increased randomness. Thus, it prompted companies to penetrate to the circulation, to strengthen the marketing capabilities.

\section{THE USE OF MODERN INFORMATION TECHNOLOGY TO IMPROVE THE MARKETING CAPABILITIES OF SMES}

SMEs in marketing management are to achieve marketing information management. China has entered the era of knowledge economy. Knowledge is the core of a variety of factors of production, the focus of market competition is the products of small batch conversion, humane, personalized, so the production and marketing management put forward higher requirements. China's SMEs can use information technology to encode knowledge, sharing of knowledge, the flow and accumulation, thereby improving the status of SMEs in the domestic and international markets, so that modern information technology is to be fully applied in the SME marketing strategy. For implementation of corporate marketing information management, specific performance is as follows: First, it is the manufacturing resource planning system. This system combines the timely production, advanced management ideas and methods of total quality management, electronic data interchange, enterprise-manufacturing resource planning, organizing, leading and controlling. So that enterprises can get daily logistics, capital flow, information. Through the network communication, case flow helps provide consumers with more satisfactory products and services, improve the market competitiveness of enterprises, in order to effectively address the existing production insurance reform models and existing mode of operation to market ability to make manual management to modern IT management that is based on scientific management transformation. Second, the comprehensive application of information, automation, manufacturing, management and other technology, people, technology, management, information flow, logistics are combined to enable enterprises to achieve scientific management, to achieve the purpose of quickly adapt to market changes, effectively improve the enterprise marketing management level. The information management process should pay attention to two issues: the IT selection from reality to the actual needs of the enterprise as the main reason for selecting IT systems; increasing IT training for staff so that they know and use IT system.

\section{MARKETING CAPABILITY IS A MAJOR RESOURCE OF COMPANIES' ABILITY TO TECHNOLOGICAL INNOVATION CAPABILITY}

Marketing capability is a major enterprise technology of innovation capability resource, but also the inherent ability of the foundation of competitive advantage. Marketing capabilities by establishing a high standard positioning, have status quo marketing ability of enterprises to inspect, obtain the following conclusions. Firstly, after scoring their marketing capabilities, it found score in all high-performance businesses in the marketing capabilities of each index is greater than low performers. The findings show that businesses can use the unique ability to establish and improve the marketing distribution network, so that there are smooth distribution channels for new products, the user can easily obtain a new product, and can easily recommend the product to improve feedback to the enterprise, the final decision is the root of the rate of product innovation. Secondly, there is a positive correlation for corporate marketing capabilities and competitive position among enterprise market. The results suggest that the ability dominate the accumulated marketing business users and thus affecting competition in the market potential, which is one of the fundamental reasons for enterprises to obtain competitive advantage. Thirdly, through the corporate marketing capabilities for high-standard orientation, it found that companies have a greater ability to make up the gap of space needs, but also found widespread lack of capacity in the business of marketing capabilities. According Benchmarking results, we propose some suggestions, based on these improvements; companies can gradually build marketing capability advantage, and then obtain a dominant position in the market competition.

Business marketing capability development is both an interactive project and it is a win-win project. Business marketing ability is to take the initiative to meet the needs of market development, to make full use of all the conditions that can be used to seize every opportunity to achieve knowledge update. Elimination system, laid-off system, the appointment are for the corporate marketing and other personnel to bring the ongoing tension, so that they feel unprecedented pressure, some companies marketing personnel often because of excessive pressure form a burnout. Corporate marketers lead the way, they continue to sell out the company's products, enterprise development will no 
longer distant. Marketing personnel for enterprises are to provide accurate, more comprehensive market information, guide enterprises to develop projects with market prospects. Problems and shortcomings exist in corporate marketing team building, which is unavoidable on the path of development enterprise marketing capabilities, which is to identify these problems and causes, in order to build up in favor of marketing talent development and management platform for the construction of a high corporate marketing staff quality. Corporate marketing staff fully utilize the existing conditions continue to improve their marketing skills. Development of corporate marketing staff capacity is a long-term dynamic process, the enterprise marketing personnel training not only upgrade their qualifications and accreditation, and more importantly, in job training and improving, so that the knowledge enterprise marketing personnel continue to be updated. To develop a series of preferential policies to attract talent, each employee is an important concept to become the consensus of business and marketing staff to encourage and support corporate marketing staff to be creative and to improve the level of marketing. At present, some companies marketing personnel lack the necessary experience and professional expertise; fewer corporate marketing staff can have a strong practical ability.

Institution building reflects the rigid management's, and then culture is a flexible management. Marketing culture is to promote corporate marketing staff career development premise. Natural and cultural cooperation between the ultimate marketing staff promote the professional development of corporate marketing staff. Moral qualities enterprise marketing personnel should become an essential quality corporate marketing staff. Ethics is part of the socialist moral system, learning about professional ethics with ethics is an important goal for corporate marketing staff career development and main content. Enterprise development, cultural development must always receive attention. In cultural development, it is necessary to improve the professional quality and operational capacity of enterprise marketing staff in the first place the goal of building and construction closely connotation. At the same time, pay more attention to how to grasp the cultural construction matches of the corporate marketing staff's career development goals that set forth in the quality and ability, obviously, at the level of implementation of the key points, it is to improve the marketing team. Enterprises should pay attention to the marketing team building, adhere to the people-oriented. To address the needs of corporate marketing staff development, local conditions develop the introduction of talent, training and personnel policy, so that these policies actually are implemented. Marketing professional development according to the level and content of construction has undertaken and work performance as the fundamental basis, it fixed the implementation and mobile preparation prepared to employ a combination of approaches corporate marketing staff.

\section{CONCLUSIONS}

Enterprises gain consumer loyalty; we must ensure that consumers think the product value is larger than the monetary value of their access to the actual payment. It should realize the value of their purchase behavior. Enterprise marketing influences corporate culture by corporate culture that reflects the humanistic enterprise level, atmosphere and external image. Corporate marketing style is formed in business development and long-term precipitation, with their own characteristics. It reveals profound essence of modern marketing, which can provide a theoretical basis for the construction of a modern enterprise marketing idea. Marketing must be to induce the consumer psychology and adaptation process of consumer psychology, which is contributed to achieving consumer behavior. Marketers can use research to identify consumer needs, provide information for the development of marketing strategies and market segments, and evaluate the effectiveness of the marketing plan and promotional activities. To be based on quality, we should establish a corporate image and distinctive business philosophy to consumer demand as the center, using a variety of ways to express their business philosophy, for the survival and development.

\section{References}

[1] Du Weiwei. Discussion on Improving corporate marketing capability [J] managers, 2011,05: 194.

[2] Yang Baozhen. corporate marketing strategy innovation [J] enterprise economy, 2011,05: 76-78.

[3] Hao Baosen. Talk construction business marketing and marketing capacity building characteristics [J] Construction \& Design, 2006,08: 110-112.

[4] Yu Xiangguo. Chinese companies marketing ability and Performance Studies [J] Oriental Culture, 2013,08: 114.

[5] Wang Hongjiang. Marketing Strategy of Multinational pharmaceutical companies [D]. Kunming University of Technology, 2013.

[6] Gao Zhaoxia. SME marketing strategies [J] charm China, 2010,01: 91.

[7] Fang Min. Current business marketing problems and countermeasures [J] new courses (in), 2013,12: 165. 